\title{
s \\ Radiation Effects in the Space Telecommunications Environment
}

\author{
Daniel M. Fleetwood and Peter S. Winokur
}

\begin{abstract}
Trapped protons and electrons in the Earth's radiation belts and cosmic rays present significant challenges for electronics that must operate reliably in the natural space environment. Single event effects (SEE) can lead to sudden device or system failure, and total dose effects can reduce the lifetime of a telecommunications system with significant space assets. One of the greatest sources of uncertainty in developing radiation requirements for a space system is accounting for the small but finite probability that the system will be exposed to a massive solar particle event. Once specifications are decided, standard laboratory tests are available to predict the total dose response of MOS and bipolar components in space, but SEE testing of components can be more challenging. Prospects are discussed for device modeling and for the use of standard commercial electronics in space.
\end{abstract}

\section{INTRODUCTION}

As steamboats and trains were to the $19^{\text {th }}$ century, and long-haul trucks and jumbo jets are to the $20^{\text {th }}$ century, so space vehicles will be to world economic growth in the $21^{\text {st }}$ century. Improved launch vehicles and reduced launch costs will make inevitable the commercial development of the near-Earth space environment. The first generations of satellites have already revolutionized the communications, entertainment, and information industries. This progress has occurred despite the necessity that satellites must survive the harsh radiation environment of space. Indeed, the first communications satellite, Telstar-I, was launched in 1962 just after an exoatmospheric nuclear weapons test, and shortly failed due to the presence of excessive amounts of high-energy electrons in the radiation belts [1]. How the cause of this satellite failure (charging of the gas in a discrete mesa-mount bipolar transistor package) was identified and how the satellite was restored to service is fascinating reading [1]-[4], and provides a cautionary tale for future system designers. Even without human intervention, the high radiation levels associated with the space environment provide a significant challenge to spacebased electronics.

In this paper the space radiation environment is briefly reviewed. The uncertainties in defining mission requirements due to the possible impact of solar activity on space system lifetime are emphasized. A few of the challenges are discussed for incorporating standard commercial electronics into space systems. It is beyond the

Daniel M. Fleetwood and Peter S. Winokur are with Sandia National Laboratories, Radiation Technology and Assurance Department, PO Box 5800, Albuquerque, NM 87185-1083 USA, E-Mail: dmfleet@aol.com. scope of this brief review to provide complete information about how one may design a space telecommunications system for use in a radiation environment. Instead, key issues are identified, and the interested reliability engineer is directed to abundant reference material in the radiation effects literature for additional information [5].

\section{ENVIRONMENT AND EFFECTS}

As illustrated schematically in Fig. 1, electronics in space are threatened by trapped protons and electrons in the Earth's radiation belts, by solar disturbances, and by cosmic rays [6]-[12]. Protons and electrons with energies high enough to penetrate the shielding of a satellite or spacecraft can cause ionization events in critical insulating layers in electronics, and/or spacecraft charging [13]. Single event effects (SEE) associated with heavy ions and high energy protons, or spacecraft charging, can cause the sudden failure of a system at any point in its mission. Total dose and/or displacement damage effects caused by high-energy protons and electrons can reduce mission lifetimes due to long-term damage to devices, ICs, or solar cells [5],[14]-[18].

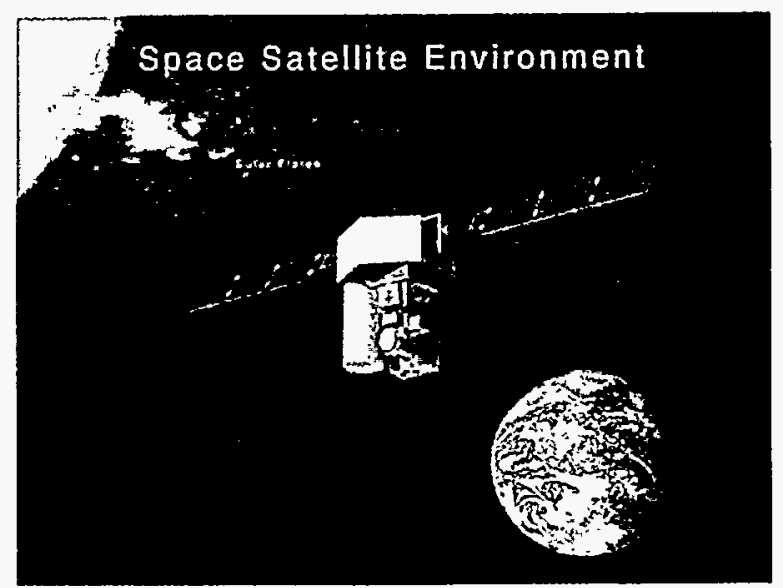

Fig. 1. Schematic illustration of some radiation hazards in the natural space environment. Illustrated are solar flares, galactic cosmic rays, and the Earth's electron and proton belts.

A cosmic ray, or a secondary ion released via a highenergy proton-induced spallation reaction [19],[20], can deposit enough energy within a sensitive node that an integrated circuit (IC) can be upset. These single event upsets (SEUs) are analogous to the soft errors that can occur in terrestrial electronics [21]-[23] or avionics [24] due to the interactions of energetic alpha particles or atmospheric neutrons [24]-[26]. However, SEU rates in space are 


\section{DISCLAIMER}

Portions of this document may be illegible in electronic image products. Images are produced from the best available original document. 
usually orders of magnitude greater than soft error rates on the ground [23],[27]. The passage of a sufficiently energetic particle through a critical device region can even lead to permanent failure of an IC due to single-particleinduced latchup [28],[29], burnout, or dielectric rupture [30],[31]. This is especially a problem for high-voltage and/or high-current electronics associated with spaceborne power supplies.

The space radiation environment varies dramatically with the latitude, longitude, and altitude of the orbit, and also varies significantly with time [6]-[12]. The most prominent geographic feature for low-Earth orbits is the South Atlantic Anomaly (SAA), which is an area of exceptionally high proton density that overlies much of South America and the South Atlantic Ocean [6]-[10]. This feature occurs because of the offset between the Earth's geographic and magnetic centers. Satellites passing through this region have greatly enhanced SEE rates and total dose damage compared to those that do not traverse the SAA. The spatial variations of the environment have been captured in computer codes developed on the basis of data acquired in space over the last 40 years [32],[33]. They allow one to forecast the total fluences and energies of electrons and protons that a system will encounter in space as a function of effective shielding thickness. One of the greatest remaining sources of uncertainty in applying these codes is predicting the amount and the magnitude of solar activity during the mission of interest.

\section{SOLAR PARTICLE EVENTS}

A fear of anyone attempting to field significant assets in space is that the system may be exposed to a massive solar particle event (SPE). These events are associated with coronal mass ejections and/or solar flares [7],[9],[32]-[36]. The most damaging components of the particle flux from a SPE to spacecraft electronics are the potentially high densities of energetic protons and heavy ions emitted from the Sun [6]-[9],[32]-[37]. The protons can deposit as much dose to sensitive electronics in the days or weeks following a SPE as in years of ordinary operation in space, and both the protons and solar heavy ions can lead to a greatly increased SEE rate.

Accounting for solar activity is a probabilistic exercise in which one attempts to estimate the likelihood of experiencing a SPE of given intensity based on the timing of the mission within the $\sim 11$-year solar cycle [7],[34]-[36]. Most space missions are planned with the expectation that they must survive at least one massive SPE. Choosing how one does this in the most economical and practical manner is a matter of debate. Often systems are designed to survive an event comparable to a large, past SPE (e.g., the massive events of 1972 or 1989), but one always worries that the Sun may conjure up a more powerful event in the future.
The degree of risk that one chooses to accept in building in margin against a super SPE is one of the most difficult decisions a spacecraft designer must make. Designing a system with more shielding than is needed means added launch costs and/or reduced functionality; too little shielding to survive a massive SPE can mean the premature demise of the system. And only the future will reveal which systems have been planned most wisely.

In this regard, Xapsos et al. recently have suggested it is extremely unlikely one would experience a SPE that is significantly more than twice the intensity of the largest event recorded in the last 40 years [36]. While planning for twice the largest recorded SPE is a more conservative approach than merely planning to survive an event equal in magnitude, the probabilistic nature of the processes leading to massive SPEs does not permit sure predictions to be made. This is of special concern because SPEs show an approximate power-law distribution (with a possible change in exponent), in which the probability of an event $P$ scales inversely with the size of the event [7],[36]. A convenient measure of the size of a random event is its power spectral density $S$. Because the frequency of an event $f$ scales inversely with $P$, the power-law form is often expressed as:

$$
S \sim 1 / f^{\alpha} .
$$

Power-law distributions similar to that shown in Eq. (1) with $0.5<\alpha<1.5$ are observed for a wide variety of astrophysical and terrestrial phenomena, in some cases over dauntingly large periods of observation. Just a few of these phenomena include low-frequency $(\sim 1 / f)$ noise observed in electronics from $\mathrm{MHz}$ to $\mu \mathrm{Hz}$ [38]-[40], fluctuations in the light curve of a quasar over 80 years [41], and the flow rate of the Nile river over 2000 years [41]. It is not suggested that these events share common physical origins with the processes causing SPEs. On the other hand, it is interesting that Press has noted that the power spectral density of the time variations of sunspot numbers exhibits low-frequency response of the form of Eq. (1) [41].

It is disquieting that other phenomena that apparently are governed by similar size/frequency statistics to SPEs almost universally do not tend toward a maximum event size [38]-[42]. Everyone believes there must be such a cutoff at an arbitrarily low frequency [41],[42], but rarely, if ever, has this behavior been observed, even on the extreme time scales of the examples provided above. In the context of SPEs, this makes one worry that, the longer the waiting period, the more likely it is there will be an event that dwarfs any observed in the last 40 years. This certainly does not mean that every space telecommunication system should design its shielding requirements to survive such a "100-year" flare; this is clearly impractical. Given economic and performance constraints on space systems, the design guidelines offered by Xapsos et al. in Ref. [36] 
appear quite reasonable. Still, it seems prudent that each system have a contingency plan in case one is unlucky enough to field a satellite constellation just before a period of unusually high solar activity.

\section{DEVICE RADIATION RESPONSE}

The total-dose hardness of conventional commercial MOS or bipolar electronics ranges from less than 1.0 $\operatorname{krad}\left(\mathrm{SiO}_{2}\right)$ to greater than $100 \mathrm{krad}\left(\mathrm{SiO}_{2}\right)$. Most standard commercial devices fail somewhere in the range of 3-30 $\operatorname{krad}\left(\mathrm{SiO}_{2}\right)$ [5],[43],[44]. However, there are recent reports of parts fabricated in at least one commercial foundry with hardness greater than $100 \mathrm{krad}\left(\mathrm{SiO}_{2}\right)$ [45], so one must take care not to over-generalize conclusions in this area.

To see how these levels relate to space applications, Fig. 2 shows total dose levels for some systems with which Sandia National Laboratories has been involved in the past [43]. Clearly, low-Earth orbits are generally more benign than higher orbits. Systems designed for orbits where the total mission dose may be less than $10 \mathrm{krad}\left(\mathrm{SiO}_{2}\right)$ likely can be designed using standard commercial parts [46]. This presumes one is prepared to perform characterization and lot qualification tests to identify parts that will work in a particular application, as even this low level of radiation tolerance should not be taken for granted. Further, one should also note that, even though a device may pass totaldose testing, it may still be subject to single-event upset or latchup in space at a rate that precludes its use.

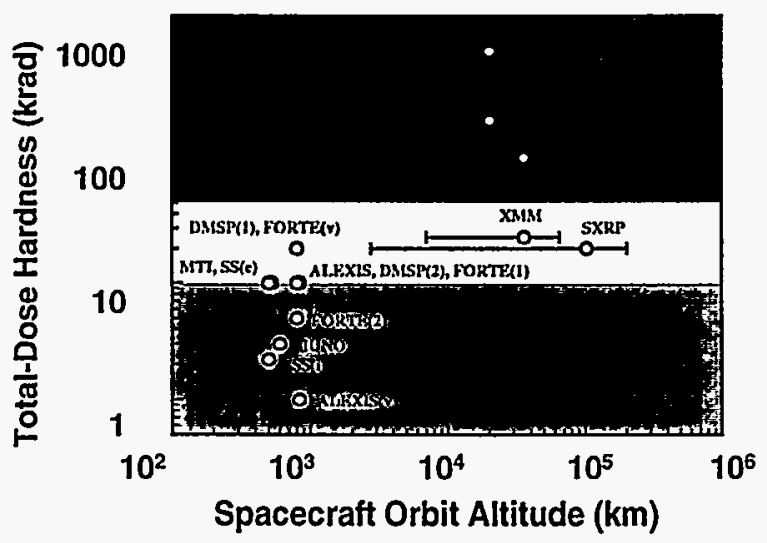

Fig. 2. Total-dose hardness requirements for several satellite systems as a function of orbit altitude. (After Ref. [43].)

Systems that spend significant amounts of time in the Earth's radiation belts (with the altitude corresponding to the maximum dose being roughly $1 / 2$ that of geosynchronous orbit) must use significant numbers of custom radiationtolerant parts. These typically are more expensive to purchase than high-volume commercial parts. However, the level of hardness designed and built into these components can allow a considerable reduction in system testing expenses, which can offset the higher initial part cost.
Systems that operate at doses from $10-100 \mathrm{krad}\left(\mathrm{SiO}_{2}\right)$ likely require a blend of standard commercial and custom radiation-tolerant technologies for maximum performance at a minimum system cost. This is where the skills of radiation effects and reliability engineers are taxed the greatest, as there are ample opportunities for errors in parts selection and testing. Common sense is often the best guide. For example, the higher the radiation requirements of the system, the greater is the testing expense to identify satisfactory standard commercial electronics, and the greater is the reward for using radiation hardened parts with reduced testing requirements. For these intermediate orbits, the systems that best solve the standard versus custom electronics problem will have the highest probability of success in the space telecommunications environment.

\section{TEST METHODS}

The most successful space systems begin their parts selection and/or testing programs before system designs are finalized [47]. One simply cannot decide that a particular part will be a key element of a system without having some confidence that the device will function as intended in the space radiation environment. Moreover, if the device is a standard commercial part, prior test data may only provide general guidance for these decisions, as commercial manufacturers occasionally make changes to process flows to improve yield and/or performance that negatively impact the radiation response of a technology. Moreover, some types of commercial devices exhibit a large amount of variability in their radiation response, especially for total dose effects [43],[44].

\section{A. Total Dose Tests}

Figure 3 is an overview of the present MOS standard test incorporated in US MIL-STD (military standard) 883, test method 1019, which is the most popular standard method to perform lot acceptance testing for the space environment [48]-[53]. This basic test flow has also been incorporated into ASTM (American Society for Testing of Materials) Standard F-1892. This test is designed to screen out MOS devices that will fail in space either due to excessive trapped positive charge in gate or parasitic insulators, or due to the buildup of interface traps. The background and rationale for this test method has been discussed extensively in the literature [48],[49],[52].

ASTM method F-1892 also contains the first standard test for linear bipolar electronics [54], which often show greatly degraded response in low-dose-rate environments (less than $\sim 0.1 \mathrm{rad}\left(\mathrm{SiO}_{2}\right) / \mathrm{s}$ ) relative to their response at conventional laboratory dose rates (e.g., greater than $\sim 50$ $\left.\operatorname{rad}\left(\mathrm{SiO}_{2}\right) / \mathrm{s}\right)$ [53]-[63]. A screening technique associated with this test method is shown in Fig. 4 [53],[54],[56],[57], [59]-[63]. In this screening technique, the device response 


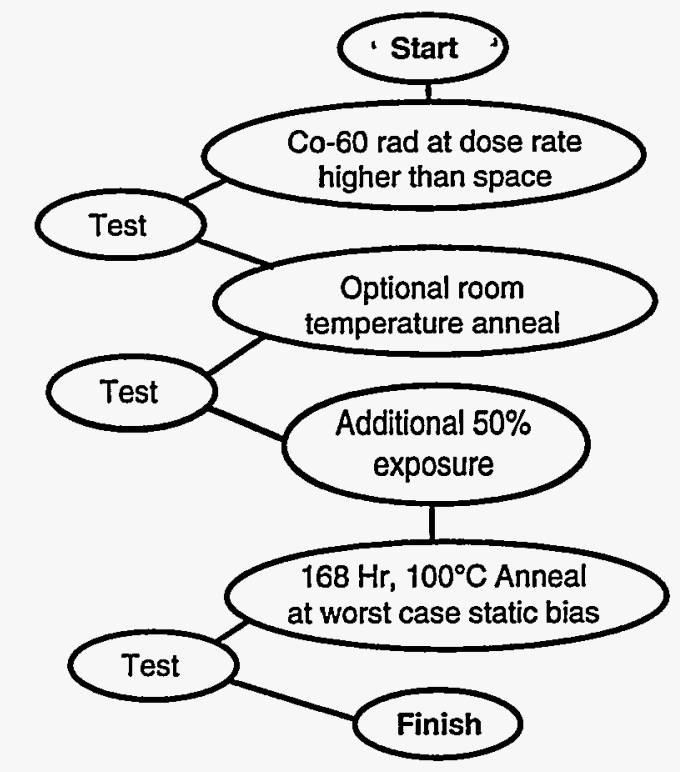

Fig. 3. Schematic illustration of the main test flow for MOS devices in US MIL-STD 883, Test Method 1019 and in ASTM Standard F-1892. (After Refs. [48],[53].)

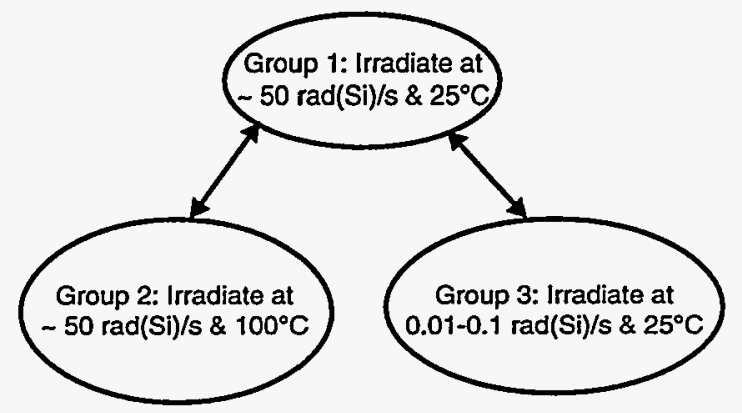

Fig. 4. Schematic illustration of a screening procedure to identify bipolar circuits and devices likely to exhibit enhanced low-doserate gain degradation in space. Parts identified as low-dose-rate sensitive via this technique must either be replaced with dose-rate insensitive parts, or be put through the detailed testing sequence described in ASTM F-1892. (After Refs. [53],[54],[56]-[63].)

at room temperature and a dose rate of $\sim 50 \operatorname{rad}(\mathrm{Si}) / \mathrm{s}$ (Group 1) is compared with a high-temperature irradiation (Group 2) and an actual low-rate exposure at $\sim 0.1-0.01$ $\mathrm{rad}(\mathrm{Si}) / \mathrm{s}$ (Group 3). If the part response in Group 2 or 3 is significantly worse than Group 1, then one should either choose another device that passes this screen, or one must go through the detailed test methodology specified in ASTM F-1892. More engineering analysis and greater design margins are required when using the bipolar tests in ASTM F-1892 than for standard MOS tests, due to the greater uncertainty in relating bipolar response in the laboratory test environment to response in space [54].

\section{B. Single Event Effects}

In contrast to total dose effects, there is no accepted standard laboratory test for single event effects [64]. To qualify a part for use in space, one must evaluate upset rates and latchup thresholds at a particle accelerator [65]-[67]. This is discussed, for example, in JEDEC (Joint Electronic Devices Engineering Council) standard EIA/JESD57, "Test Procedures for the Measurement of SEE in Semiconductor Devices from Heavy Ion Irradiation." Heavy ion testing is expensive and, except for highly replicated designs like some memories, can be difficult to execute and interpret correctly. Microprocessors, linear ICs, combinational logic, and even flash memories can present special challenges to the parts engineer, as what constitutes an upset often depends on how a local disturbance propagates through the rest of the IC and the remainder of the system [68]-[75]. Often for complex device types, one attempts to set up a full board, run it in the accelerator environment, and measure the impact of the device under SEE test on the system performance [47]. However, identifying the origin of errors observed under these conditions can be difficult. Moreover, the ever-increasing speed of advanced microelectronics places great challenges on equipment during SEU testing [76],[77]. Destructive SEE testing [28],[30] carries its own sets of challenges, to ensure that devices subject to singleevent latchup, gate rupture, snapback, or burnout are not built into space telecommunications systems.

While SEE testing is more expensive and difficult than total-dose testing, there also can be less part-to-part and lotto-lot variation in SEE response than in total-dose response. Unless a manufacturer makes a major change to the design, layout, or starting material of the technology, the SEE response of a part type tends to remain roughly constant. Thus, one can generally use database information with more confidence for predictions of SEE response than for totaldose response. Periodic compilations in the annual IEEE Radiation Effects Data Workshop Records are especially useful in this regard [78]-[82]. However, a dramatic counterexample is provided by Harboe-Sorensen [83], who showed a particularly frightening case in which commercial parts with the same marking contained die from different manufacturers! So, clearly one must take pains to verify that reference data correspond to the part in question.

Once a device is selected and its SEU response is characterized by testing or extracted from a database, the system engineer must use this information together with knowledge of the expected environment to forecast the expected error rate in space. Extensive work on this task has been done both for high-energy protons and heavy ions [20],[27],[84],[85]. Often, devices are selected for which the SEU rate in space is finite but manageable, and systemlevel error correction techniques are employed to mitigate the consequences of the SEEs [47],[86].

\section{Special Considerations for Protons}

In the past, the effects of protons were combined into the total-dose and SEE environments. An exception was 
made for displacement damage effects to solar cells and/or sensitive linear circuits, where additional testing may be required [14],[87]. However, recent evidence on some part types like charge-coupled devices and optocouplers have shown it is sometimes easier to do an actual proton test than to replicate the environment with a combination of, for example, gamma, neutron, and heavy ion tests [14]-[18]. Thus, proton effects testing is an emerging area of radiation effects analysis certain to receive a lot more attention in the future [87]. This is especially true for new technologies, for which new failure mechanisms must be anticipated.

\section{MODELING AND SIMULATION}

Given the high expense associated with SEE testing, modeling and simulation tools are being increasingly used to facilitate the design and layout of radiation hardened technologies [88],[89]. In the hands of an experienced user, the present generation of three-dimensional simulation codes have proven to be an essential element of technology development activities. There is a natural desire to extend this capability to the qualification of standard commercial electronics. However, it is typically not possible to obtain the amount of process and design information required to perform predictive modeling on standard commercial electronics, so actual device testing, while often expensive and difficult, remains a necessity.

There has also been progress in developing total-dose models of MOS technologies reported in the literature [90][92]. This will clearly be an area of continued interest in the future. However, given that total dose tests usually are relatively inexpensive to perform and easy to interpret, and given the higher levels of lot-to-lot variability for total dose relative to SEE, the economic case for total-dose modeling may not be quite as great as for SEE modeling.

\section{SURVIVABILITY}

At the beginning of the article, we recalled the example of Telstar-I, which was rendered temporarily inoperative after an exoatmospheric nuclear explosion [1]-[4]. While one would like to think that the era of above-ground nuclear weapons testing is past, both military and commercial builders and users of space telecommunications systems must consider the impact of a similar detonation on their space systems. In this case, not only must total dose and SEE be considered, but transient radiation effects must also be considered, which can also cause electronics to upset or even burn out [5]. These issues are typically only addressed in special military satellites at present. However, the convergence between military and commercial assets that began in earnest with the Global Positioning System is only expected to increase in the future. So assessments of the performance of commercial space telecommunications in military environments may be necessary in the future [93].

\section{SUMMARY AND CONCLUSIONS}

The natural space radiation environment presents a great challenge to present and future telecommunications systems with significant assets in space. Defining the requirements for such a system not only requires knowledge about the environment and its effects on electronics and optoelectronics technologies, but also suitable risk assessment of the uncertainties involved. This is especially true for planning on the most likely number and magnitude of solar particle events during the mission, as well as developing contingency plans in case one experiences a massive solar particle event.

Standard laboratory test methods are available to assist in assessing and ensuring the total-dose response of MOS and bipolar electronics in space, but SEE testing requires more expensive tests at a dedicated user facility. SEE response tends to be more stable from lot-to-lot than total dose response, so databases can be of great assistance for SEE. However, for standard commercial electronics, the reader is cautioned to ensure that the data correspond to the part actually fielded [83]. Feedback on the environment and on parts performance from the many different space systems being launched over the next ten years will be crucial to reducing the risks and costs of follow-on systems.

To be safe, if one finds a particular type of standard commercial IC that seems ideal for one's system, making a lifetime buy is recommended, as there is no assurance that the manufacturer will continue to build the parts in the same way. Using custom radiation hardened parts when possible avoids this source of uncertainty, though at the expense of increased purchase costs and potentially reduced system performance, at least at the outset of the mission. The most successful systems in space will be those that are best able to blend standard commercial electronics with custom radiation-hardened electronics in a mix that is suitable for the expected system operating conditions. The systems that best solve these problems will be the ones most likely to drive state-of-the-art $21^{\text {st }}$ century telecommunications.

\section{ACKNOWLEDGMENTS}

We thank P. E. Dodd, M. R. Shaneyfelt, J. R. Schwank, F. W. Sexton, S. B. Roeske, R. L. Pease, L. M. Cohn, W. F. Heidergott, P. W. Marshall, C. J. Marshall, J. L. Leray, R. F. Voss, and R. D. Schrimpf for stimulating discussions. Sandia is a multiprogram laboratory operated by Sandia Corporation, a Lockheed Martin Company, for the US Dept. of Energy under Contract No. DE-AC04-94AL85000.

\section{REFERENCES}

[1] H. L. Hughes, "Historical Perspective," in lonizing Radiation Effects in MOS Devices \& Circuits, eds: T. P. Ma and P. V. Dressendorfer (Wiley, New York, 1989), pp. 47-86, and references therein. 
[2] W. Brown, J. Gabbe, and W. Rosenzweig, "Results of the Telstar Radiation Experiments," Bell System Tech. J. vol. 42, 1505 (1963).

[3] P. T. Hutchinson and R. A. Swift, "Results of the Telstar Space Experiments," Bell System Tech. J. vol. 42, 1475 (1963).

[4] J. Mayo, H. Mann, F. Witt, D. Peck, H. Gummel, and W. Brown, "The Command System Malfunction of the Telstar Satellite," Bell System Tech. J. vol. 42, 1631 (1963).

[5] For example, NSREC Archive of Radiation Effects Short Course Notebooks on CD-ROM, IEEE Product Order Code EC110, ISBN: 07803-4653-X, covers years 1980-1998.

[6] E. G. Stassinopoulos and J. P. Raymond, "The Space Radiation Environment for Electronics," Proc. IEEE vol. 76, 1423 (1988).

[7] J. Feynman and S. B. Gabriel, "High-Energy Charged Particles in Space at One Astronomical Unit," IEEE Trans. Nucl. Sci. vol. 43, 344 (1996).

[8] M. S. Gussenhoven, E. G. Mullen, and D. H. Brautigam, "Improved Understanding of the Earth's Radiation Belts from the CRRES Satellite," IEEE Trans. Nucl. Sci. vol. 43, 353 (1996).

[9] E. G. Stassinopoulos, G. J. Brucker, D. W. Nakamura, C. A. Stauffer, G. B. Gee, and J. L. Barth, "Solar Flare Proton Evaluation at Geostationary Orbits for Engineering Applications," IEEE Trans. Nucl. Sci. vol. 43, 369 (1996).

[10] C. S. Dyer, A. Sims, and C. Underwood, "Measurements of the SEE Environment from Sea Level to GEO Using the CREAM and CREDO Experiments," IEEE Trans. Nucl. Sci. vol. 43, 383 (1996).

[11] E. J. Daly, J. Lemaire, D. Heynderickx, and D. J. Rodgers, "Problems with Models of the Radiation Belts," IEEE Trans. Nucl. Sci. vol. 43, 403 (1996).

[12] D. Boscher, S. Bourdarie, and T. Beutier, "Dynamic Modeling of Trapped Particles," IEEE Trans. Nucl. Sci. vol. 43, 416 (1996).

[13] A. R. Frederickson, "Upsets Related to Spacecraft Charging," IEEE Trans. Nucl. Sci. vol. 43, 426 (1996).

[14] S. R. Messenger, M. A. Xapsos, E. A. Burke, R. J. Walters, and G. P. Summers, "Proton Displacement Damage and lonizing Dose for Shielded Devices in Space," IEEE Trans. Nucl. Sci. vol. 44, 2169 (1997).

[15] J. R. Srour, G. J. Vendura, Jr., D. H. Lo, C. M. C. Toporow, M. Dooley, R. P. Nakano, and E. E. King, "Damage Mechanisms in Radiation-Tolerant Amorphous Si Solar Cells," IEEE Trans. Nucl. Sci. vol. 45, 2624 (1998).

[16] J. R. Srour, "Radiation Effects R\&D in the 1970s: A Retrospective View," IEEE Trans. Nucl. Sci. vol. 41, 2660 (1994).

[17] G. R. Hopkinson, C. J. Dale, and P. W. Marshall, "Proton Effects in Charge-Coupled Devices," IEEE Trans. Nucl. Sci. vol. 43, 614 (1996).

[18] R. A. Reed, P. W. Marshall, A. H. Johnston, J. L. Barth, C. J. Marshall, K. A. LaBel, M. D'Ordine, H. S. Kim, and M. A. Carts, "Emerging Optocoupler Issues with Energetic Particle-Induced Transients and Permanent Radiation Degradation," IEEE Trans. Nucl. Sci. vol. 45, 2833 (1998).

[19] P. J. McNulty, W. G. Abdel-Kader, and G. E. Farrell, "Proton Induced Spallation Reactions," Radiat. Phys. Chem. 43, 139 (1994).

[20] E. L. Petersen, "Approaches to Proton Single-Event Rate Calculation," IEEE Trans. Nucl. Sci. vol. 43, 496 (1996).

[21] L. W. Massengill, "Cosmic and Terrestrial Single-Event Radiation Effects in DRAMs," IEEE Trans. Nucl. Sci. vol. 43, 576 (1996).

[22] J. F. Ziegler et al., "IBM Experiments in Soft Fails in Computer Electronics," IBM J. Res. Dev. Vol. 40, 3 (1996)

[23] E. Normand, "SEU at Ground Level;" IEEE Trans. Nucl. Sci. vol. 43 , 2742 (1996)

[24] E. Normand, "SEE in Avionics," IEEE Trans. Nucl. Sci. vol. 43, 46I (1996).

[25] R. Baumann, T. Hossain, S. Murata, and H. Kitagawa, "Boron Compounds as a Dominant Source of Alpha Particles in Semiconductor Devices," Proc. IRPS. IEEE Catalog No. 95CH34710,297 (1995).

[26] J. F. Ziegler, "Terrestrial Cosmic Rays," IBM J. Res. Dev. Vol. 40. 19 (1996).

[27] E. L. Petersen, "Predictions and Observations of SEU Rates in Space," IEEE Trans. Nucl. Sci. vol. 44, 2174 (1997).
[28] A. H. Johnston, "The Influence of VLSI Technology Evolution on Radiation-Induced Latchup in Space Systems," IEEE Trans. Nucl. Sci. vol. 43, 505 (1996).

[29] G. Bruguier and J. M. Palau, "Single Particle-Induced Latchup," IEEE Trans. Nucl. Sci. vol. 43, 522 (1996).

[30] J. L. Titus and C. F. Wheatley, "Experimental Studies of SingleEvent Gate Rupture and Bumout in Vertical Power MOSFETs," IEEE Trans. Nucl. Sci. vol. 43, 533 (1996).

[31] G. H. Johnson, J. M. Palau, C. Dachs, K. F. Galloway, and R. D. Schrimpf, "A Review of the Techniques Used for Modeling SEE in Power MOSFETs," IEEE Trans. Nucl. Sci. vol. 43, 546 (1996).

[32] A. J. Tylka, J. H. Adams, Jr., P. R. Boberg, B. Brownstein, W. F. Dietrich, E. O. Flueckiger, E. L. Petersen, M. A. Shea, D. F. Smart, and E. C. Smith, "CREME96: A Revision of the Cosmic Ray Effects on Micro-Electronics Code," IEEE Trans. Nucl. Sci. vol. 44, 2150 (1997), and references therein.

[33] J. L. Barth, "Modeling Space Radiation Environments," 1997 IEEE Nuclear and Space Radiation Effects Conference Short Course.

[34] D. V. Reames, "Solar Energetic Particles: A Paradigm Shift," Revs. Geophys. (Suppl.) vol. 33, 585 (1995).

[35] C. Tranquille, "Solar Proton Events and Their Effect on Space Systems," Radiat. Phys. Chem. vol. 43, 35 (1994).

[36] M. A. Xapsos, G. P. Summers, and E. A. Burke, "Probability Model for Peak Fluxes of Solar Proton Events," IEEE Trans. Nucl. Sci. vol. 45, 2948 (1998).

[37] A. J. Tylka, W. F. Dietrich, P. R. Boberg, E. C. Smith, J. H. Adams, Jr., "SEUs Caused by Solar Energetic Heavy Ions," IEEE Trans. Nucl. Sci. vol. 43, 2758 (1996).

[38] A. van der Ziel, "Flicker Noise in Electronic Devices," Adv. Electron. Electron Phys. vol. 49, 225 (1979).

[39] D. M. Fleetwood, J. T. Masden, and N. Giordano, " $1 / f$ Noise in Platinum Films and Ultrathin Platinum Wires: Evidence for a Common, Bulk Origin," Phys. Rev. Lett. vol. 50, 450 (1983).

[40] B. Neri, B. Pelligrini, and R. Saletti, "Ultra Low-Noise Preamplifier for Low-Frequency Noise Measurements in Electron Devices," IEEE Trans. Instrum. Msmt. vol. 40, 2 (1991), and references therein.

[41] W. H. Press, "Flicker Noises in Astronomy and Elsewhere." Comments Astrophys. vol. 7, No. 4, 103 (1978), and references therein.

[42] M. B. Weissman, " $1 / f$ Noise and Other Slow, Nonexponential Kinetics in Condensed Matter," Rev. Mod. Phys. vol. 60, 537 (1988); R. F. Voss, Ph. D. thesis, Univ. of California-Berkeley, 1975.

[43] M. R. Shaneyfelt, P. S. Winokur, T. L. Meisenheimer, F. W. Sexton, S. B. Roeske, and M. G. Knoll, "Hardness Variability in Commercial Technologies," IEEE Trans. Nucl. Sci. vol. 41, 2536 (1994).

[44] R. L. Pease, "Total-Dose Issues for Microelectronics in Space Systems," IEEE Trans. Nucl. Sci. vol. 43, 442 (1996).

[45] J. V. Osborn, R. C. Lacoe, D. C. Mayer, and G. Yabiku, "Total Dose Hardness of Three Commercial CMOS Microelectronics Foundries," IEEE Trans. Nucl. Sci. vol. 45, 1458 (1998).

[46] C. I. Underwood and M. K. Oldfield, "Observed Radiation-Induced Degradation of Commercial Off-the-Shelf Devices Operating in LowEarth Orbit," IEEE Trans. Nucl. Sci. vol. 45, 2737 (1998).

[47] K. A. LaBel, A. H. Johnston, J. L. Barth, R. A. Reed, and C. E. Barnes, "Emerging Radiation Hardness Assurance Issues: A NASA Approach for Spaceflight Programs," IEEE Trans. Nucl. Sci. vol. 45, 2727 (1998).

[48] D. M. Fleetwood, P. S. Winokur, and T. L. Meisenheimer, "Hardness Assurance for Low-Dose Space Applications," IEEE Trans. Nucl. Sci. vol. 38, 1552 (1991)

[49] D. M. Fleetwood, P. S. Winokur, C. E. Barnes, and D. C. Shaw, "Accounting for Time-Dependent Effects on CMOS Total-Dose Response in Space Environments," Radiat. Phys. Chem. vol. 43, 129 (1994).

[50] P. S. Winokur, D. M. Fleetwood, and F. W. Sexton, "RadiationHardened Microelectronics for Space Applications," Radiat. Phys. Chem. vol. 43, 175 (1994)

[51] R. L. Pease and D. R. Alexander, "Hardness Assurance for Space System Microelectronics," Radiat. Phys. Chem. vol. 43, 191 (1994). 
[52] D. M. Fleetwood, "A First-Principles, Approach to Total-Dose Hardness Assurance," 1995 IEEE Nuclear and Space Radiation Effects Conference Short Course.

[53] D. M. Fleetwood, "Total Ionizing Dose Effects on MOS and Bipolar Devices in the Natural Space Radiation Environment," Proc. $3^{\text {rd }}$ Workshop on Semiconductor Devices for Space Application, Takasaki, Japan, October 12-13, 1998, pp 1-9.

[54] R. L. Pease, L. M. Cohn, D. M. Fleetwood, M. A. Gehlhausen, T. L. Turflinger, D. B. Brown, and A. H. Johnston, "A Proposed Hardness Assurance Test Methodology for Bipolar Linear Circuits and Devices in a Space Ionizing Radiation Environment," IEEE Trans. Nucl. Sci. vol. 44, 1981 (1997).

[55] E. W. Enlow, R. L. Pease, W. Combs, R. D. Schrimpf, and R. N. Nowlin, "Response of Advanced Bipolar Devices to Ionizing Radiation," IEEE Trans. Nucl. Sci. vol. 38, 1342 (1991).

[56] D. M. Fleetwood, S. L. Kosier, R. N. Nowlin, R. D. Schrimpf, R. A. Reber, Jr., M. DeLaus, P. S. Winokur, A. Wei, W. E. Combs, and R. L. Pease, "Physical Mechanisms Contributing to Enhanced Bipolar Gain Degradation at Low Dose Rates," IEEE Trans. Nucl. Sci. vol. 41, 1871 (1994).

[57] R. D. Schrimpf, R. J. Graves, D. M. Schmidt, D. M. Fleetwood, R. L. Pease, W. E. Combs, and M. DeLaus, "Hardness-Assurance Issues for Lateral PNP Bipolar Junction Transistors," IEEE Trans. Nucl. Sci. vol. 42, 1641 (1995).

[58] A. H. Johnston, B. G. Rax, and C. I. Lee, "Enhanced Damage in Linear Bipolar ICs at Low Dose Rate," IEEE Trans. Nucl. Sci. vol. 42, 1650 (1995).

[59] D. M. Fleetwood, L. C. Riewe, J. R. Schwank, S. C. Witczak, and R. D. Schrimpf, "Radiation Effects at Low Electric Fields in Thermal, SIMOX, and Bipolar-Base Oxides," IEEE Trans. Nucl. Sci. vol. 43, 2537 (1996).

[60] A. H. Johnston, C. I. Lee, and B. G. Rax, "Enhanced Damage in Bipolar Devices at Low Dose Rates: Effects at Very Low Dose Rates," IEEE Trans. Nucl. Sci. vol. 43, 3049 (1996).

[61] S. C. Witczak, R. D. Schrimpf, K. F. Galloway, D. M. Fleetwood, R. L. Pease, J. M. Puhl, D. M. Schmidt, W. E. Combs, and J. S. Suehle, "Accelerated Tests for Simulating Low Dose Rate Gain Degradation of Lateral and Substrate PNP Bipolar Junction Transistors," IEEE Trans. Nucl. Sci. vol. 43, 3151 (1996).

[62] S. C. Witczak, R. D. Schrimpf, D. M. Fleetwood, K. F. Galloway, R. C. Lacoe, D. C. Mayer, J. Puhl, R. Pease, and J. Suehle, "Hardness Assurance Testing of Bipolar Junction Transistors at Elevated Temperatures," IEEE Trans. Nucl. Sci. vol. 44, 1989 (1997).

[63] S. C. Witczak, R. C. Lacoe, D. C. Mayer, D. M. Fleetwood, R. D. Schrimpf, and K. F. Galloway, "Space Charge Limited Degradation of Bipolar Oxides at Low Electric Fields," IEEE Trans. Nucl. Sci. vol. 45,2339 (1998).

[64] S. Buchner, D. McMorrow, J. Melinger, and A. B. Campbell, "Laboratory Tests for Single-Event Effects," IEEE Trans. Nucl. Sci. vol. 43, 678 (1996).

[65] R. Harboe-Sorensen, "Test Methods for Single-Event Upset/Latchup," Radiat. Phys. Chem. vol. 43, 165 (1994).

[66] R. Koga, "SEE Ground Test Issues," IEEE Trans. Nucl. Sci. vol. 43. 661 (1996).

[67] S. Duzellier and R. Ecoffet, "Recent Trends in SEE Ground Testing," IEEE Trans. Nucl. Sci. vol. 43, 671 (1996).

[68] D. M. Newberry, D. H. Kaye, and G. A. Soli, "Single Event Induced Transients in VO Devices: A Characterization," IEEE Trans. Nucl. Sci. vol. 37, 1974 (1990).

[69] F. W. Sexton, W. T. Corbett, R. K. Treece, K. J. Hass, K. L. Hughes, C. L. Axness, G. L. Hash, M. R. Shaneyfelt, and T. F. Wunsch, "SEU Simulation \& Testing of Resistor-Hardened D-Latches in the SA3300 Microprocessor," IEEE Trans. Nucl. Sci. vol. 38, 1521 (1991).

[70] T. L. Turflinger, "SEE in Analog and Mixed-Signal Integrated Circuits," IEEE Trans. Nucl. Sci. vol. 43, 594 (1996)

[7I] K. Jobe, M. Shoga, and R. Koga, "A Systems-Oriented SEE Test Approach for High Speed Digital Phase Locked Loops," IEEE Trans. Nucl. Sci. vol. 43, 2868 (1996).

[72] R. Velazco, A. Assoum, Ph. Cheynet, M. Olmos, and R. Ecoffet, "SEU Experiments on an Artificial Neural Network Implemented by
Means of Digital Processors," IEEE Trans. Nucl. Sci. vol. 43, 2889 (1996).

[73] H. R. Schwartz, D. K. Nichols, and A. H. Johnston, "SEU in Flash Memories," IEEE Trans. Nucl. Sci. vol. 44, 2315 (1997).

[74] R. Koga, S. H. Penzin, K. B. Crawford, W. R. Crain, S. C. Moss, S. D. Pinkerton, S. D. LaLumondiere, and M. C. Maher, "SEU Sensitivity Dependence of Linear ICs on Bias Conditions," IEEE Trans. Nucl. Sci. vol. 44, 2325 (1997).

[75] V. Asenek, C. Underwood, R. Velazco, S. Rezgui, M. Oldfield, $\mathrm{Ph}$ Cheynet, and R. Ecoffet, "SEU Induced Errors Observed in Microprocessor Systems," IEEE Trans. Nucl. Sci. vol. 45, 2876 (1998).

[76] R. A. Reed, M. A. Carts, P. W. Marshall, C. J. Marshall, S. Buchner, M. LaMacchia, B. Mathes, and D. McMorrow, "SEU Cross Sections at Various Data Rates," IEEE Trans. Nucl. Sci. vol. 43, 2862 (1996).

[77] A. H. Johnston, "Radiation Effects in Advanced Microelectronics Technologies," IEEE Trans. Nucl. Sci. vol. 45, 1339 (1998).

[78] J. L. Barth, J. W. Adolphsen, and G. B. Gee, "SEE on Commercial SRAMs and Power MOSFETs: Final Results of the CRUX Flight Experiment on APEX," 1998 IEEE Radiation Effects Data Workshop, IEEE Catalog No. 98TH8385 (1998), pp. 1-10.

[79] J. R. Coss, G. M. Swift, L. E. Selva, J. L. Titus, E. Normand, D. L. Oberg, J. L. Wert, "Compendium of Single Event Failures in Power MOSFETs," 1998 IEEE Radiation Effects Data Workshop, IEEE Catalog No. 98TH8385 (1998), pp. 15-38.

[80] M. V. O'Bryan, K. A. LaBel, R. A. Reed, J. L. Barh, C. M. Seidleck, P. W. Marshall, C. J. Marshall, and M. Carts, "SEE and Radiation Damage Results for Candidate Spacecraft Electronics," 1998 IEEE Radiation Effects Data Workshop. IEEE Catalog No. 98TH8385 (1998), pp. 39-50.

[81] R. Harboe-Sorensen, M. Bruffemann, R. Muller, and F. J. Rombeck, "Radiation Evaluation of $3.3 \mathrm{~V} 16 \mathrm{M}$-bit DRAMs for Solid State Mass Memory Space Applications," 1998 IEEE Radiation Effects Data Workshop, IEEE Catalog No. 98TH8385 (1998), pp. 74-79.

[82] D. K. Nichols, J. R. Coss, T. F. Miyahira, H. R. Schwartz, G. M. Swift, R. Koga, W. R. Crain, K. B. Crawford, and S. H. Penzin, "Device SEE Susceptibility from Heavy Ions (1995-1996)," 1997 IEEE Radiation Effects Data Workshop, IEEE Catalog No. 97TH8293 (1997), pp. 1-13.

[83] R. Harboe-Sorensen, "Radiation Pre-screening of Commercially Available Memories for Space Applications," Proc. $3^{\text {rd }}$ Workshop on Semiconductor Devices for Space Application. Takasaki. Japan. October 12-13, 1998, pp. 137-147.

[84] E. L. Petersen, J. C. Pickel, J. H. Adams, Jr., and E. C. Smith, "Rate Prediction for SEE - A Critique," IEEE Trans. Nucl. Sci. vol. 39. 1577 (1992).

[85] J. C. Pickel, "SEE Rate Prediction," IEEE Trans. Nucl. Sci. vol. 43. 483 (1996).

[86] W. F. Heidergott, "System Level Mitigation Strategies," 1999 IEEE Nuclear and Space Radiation Effects Conference Shorn Course.

[87] P. W. Marshall and C. J. Marshall, "Proton Effects and Test Issues for Satellite Designers," 1999 IEEE Nuclear and Space Radiation Effects Conference Short Course.

[88] P. E. Dodd, "Device Simulation of Charge Collection and SEU." IEEE Trans. Nucl. Sci. vol. 43, 561 (1996).

[89] P. E. Dodd, "Basic Mechanisms for SEE," 1999 IEEE Nuclear and Space Radiation Effects Conference Short Course.

[90] C. Brisset, V. Ferlet-Cavrois, O. Flament, O. Musseau, J. L. Leray, J. L. Pelloie, R. Escoffier, A. Michez, C. Cirba, and G. Bordure, "2D Simulation of Total Dose Effects on NMOSFET with Lateral Parasitic Transistor," IEEE Trans. Nucl. Sci. vol. 43, 2651 (1996).

[91] R. J. Milanowski, M. P. Pagey, L. W. Massengill, R. D. Schrimpf. M. E. Wood, B. W. Offord, R. J. Graves, K. F. Galloway, C. J. Nicklaw, and E. P. Kelley, "TCAD-Assisted Analysis of Back-Channel Leakage in Irradiated Mesa SOI nMOSFETs," IEEE Trans. Nucl. Sci. vol. 45, 2593 (1998).

[92] J. L. Leray, "Total Dose Effects: Modeling for Present and Future," 1999 IEEE Nuclear and Space Radiation Effects Conf. Short Course.

[93] L. M. Cohn and G. Kweder, "Nuclear Threat to LEO Satellites," $11^{\text {th }}$ SEE Symposium Proc., Los Angeles. CA. April 20-23. 1998, pp. 549-565. 